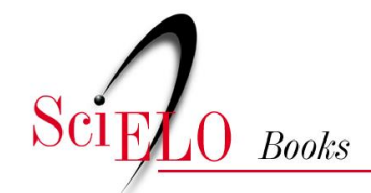

\title{
O nutricionista na Estratégia Saúde da Família
}

\author{
Maria Idalice Silva Barbosa \\ Geórgia de Mendonça Nunes Leonardo \\ Maria Lucia Magalhães Bosi
}

SciELO Books / SciELO Livros / SciELO Libros

BARBOSA, MIS., LEONARDO, GMN., and BOSI, MLM. O nutricionista na Estratégia Saúde da Família. In: PRADO, SD., et al. orgs. Estudos socioculturais em alimentação e saúde: saberes em rede. [online]. Rio de Janeiro: EDUERJ, 2016. Sabor metrópole series, vol. 5, pp. 401-425. ISBN: 978-85-7511-456-8. Available from: doi: 10.7476/9788575114568. Also available in ePUB from: http://books.scielo.org/id/37nz2/epub/prado-9788575114568.epub

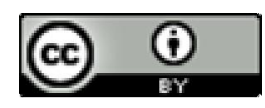

All the contents of this work, except where otherwise noted, is licensed under a Creative Commons Attribution 4.0 International license.

Todo o conteúdo deste trabalho, exceto quando houver ressalva, é publicado sob a licença Creative Commons Atribição 4.0.

Todo el contenido de esta obra, excepto donde se indique lo contrario, está bajo licencia de la licencia $\underline{\text { Creative Commons }}$ Reconocimento 4.0. 


\title{
O nutricionista na Estratégia Saúde da Família
}

\author{
Maria Idalice Silva Barbosa \\ Geórgia de Mendonça Nunes Leonardo \\ Maria Lucia Magalhães Bosi
}

\section{Introdução}

Em 1994, a implantação do Programa Saúde da Família, como proposta de efetivação dos serviços de atenção primária do Sistema Único de Saúde (SUS), traz para o debate estudos sobre a promoção da saúde e a prevenção de doenças, colaborando para a inversão do modelo assistencial que fora impulsionado no Brasil pelo movimento conhecido como Reforma Sanitária Brasileira. Atualmente, esse processo caminha em busca de consolidação por meio da Estratégia Saúde da Família (ESF), como aposta para a organização dos serviços de atenção básica, orientando o modelo assistencial pelo foco na família e em seu contexto, como objeto de atenção à saúde, consoante um conceito ampliado, e não mais restrito à Biomedicina.

Desde então, somam-se esforços para diversificar e qualificar as ações de saúde no âmbito da atenção primária, na tentativa de organizar os serviços fundamentados no conceito ampliado de saúde, o qual vai além dos parâmetros descritos pelas ciências biológicas e médicas, no sentido de compreendê-lo como "potência para lidar com a existência"1 (Czeresnia, 2013, p. 12). A saúde se expressa, portanto, como Góis (2008) afirma, na capacidade de realização do potencial evolutivo do indivíduo em suas múltiplas formas de ser e viver no ambiente social. 
A Política Nacional de Atenção Básica, com sua proposta de ampliação da equipe mínima ${ }^{1}$ nos serviços de atenção primária, busca operacionalizar essa concepção de saúde mais ampla, que envolve outros profissionais na produção do cuidado com a saúde. É o caso do Núcleo de Apoio Saúde da Família $^{2}$ (NASF), que tem por objetivo "ampliar a abrangência e o escopo das ações da atenção básica, bem como sua resolubilidade, apoiando a inserção da Estratégia de Saúde da Família na rede de serviços e o processo de territorialização e regionalização a partir da atenção básica”, conforme a Portaria (GM n. 154, 24/01/2008) do Ministério da Saúde (Brasil, 2008).

Esse processo histórico de efetivação e busca pela qualificação dos serviços de atenção básica tem impulsionado os estudos voltados à delimitação dos espaços profissionais das diversas categorias na atenção básica, como componente específico no processo de produção dos cuidados com a saúde. Trata-se de um campo ainda pouco conhecido para os profissionais da saúde, os quais, historicamente, têm nos hospitais o locus privilegiado de sua atuação.

No que diz respeito ao exercício profissional no campo de alimentação e nutrição, diversos estudos tecem argumentos favoráveis à sua inserção na atenção básica (Assis et al., 2002; Fernandez et al., 2005; Pádua e Boog, 2006). Tais estudos defendem a pertinência do nutricionista na equipe multiprofissional com os seguintes argumentos: lacunas no saber de outras profissões, sobretudo Medicina e Enfermagem, sob a alegação de não reunirem as competências e os conhecimentos necessários, nem autoridade legal para exercer funções específicas, a exemplo de prescrições dietoterápicas; acúmulo de tarefas dos demais profissionais da equipe, que assumem funções que exigem o saber do campo da nutrição, no que se refere a orientar a população; número insuficiente de profissionais para atuar nesse campo.

Outro núcleo de argumentação dos estudos relacionados a essa questão converge para as políticas públicas de alimentação e nutrição, bem como de alimentação saudável, na defesa de que essas ações não têm como prescindir de um nutricionista (Assis et al., 2002; Pádua e Boog, 2006; Santos, 2005). Um estudo realizado por Boog (2008) conclui que a atuação do nutricionista

1 Segundo o PNAB, a equipe mínima da ESF deve ser composta pelos seguintes profissionais: médico, enfermeiro, agentes comunitários de saúde, técnico em enfermagem, dentista e técnico de higiene bucal.

2 Integram a equipe de profissionais do NASF: nutricionistas, psicólogos, fisioterapeutas, educadores físicos, terapeutas ocupacionais, assistentes sociais, entre outros. 
no campo da saúde pública ainda é incipiente, defendendo que a promoção de uma alimentação saudável pressupõe ações educativas para as quais a categoria não dispõe de tecnologia. Esses argumentos abrem espaço para uma discussão das lacunas na formação desse profissional. Recine e Vasconcelos (2011) defendem a necessidade de expansão e qualificação das ações de alimentação e nutrição no SUS, acompanhadas de adequação na formação dos profissionais de nutrição para o campo da saúde coletiva. Os autores consideram a necessidade de se investir na formação do nutricionista no que se refere a educação em saúde, trabalho em equipe e desenvolvimento de açóes de promoção de saúde, competências necessárias à atuação nos serviços de atenção básica.

Esses estudos apoiam a inserção do nutricionista na ESF ao argumento da especificidade de seu saber clínico no que diz respeito a prescrições e orientações dietoterápicas, saber que estaria ausente na formação de outros profissionais da equipe (médicos e enfermeiros). Esses argumentos evidenciam a relevância das açóes de promoção da saúde no campo de alimentação e nutrição e, ao mesmo tempo, defendem a inserção de nutricionistas na atenção básica, fundamentando sua atuação na clínica vinculada a algumas ações, como, por exemplo, prescriçóes dietoterápicas voltadas a enfermidades como obesidade, diabetes ou hipertensão, entre outras. Sem desconsiderar a importância dessa dimensão da prática, é preciso levar em conta a necessidade de se articular a base cognitiva com a peculiaridade das ações que caracterizam a atenção básica em saúde.

Os argumentos contidos nesses estudos nos remetem a características históricas que marcam o surgimento da profissão. Estudos que analisam o percurso histórico do nutricionista no Brasil (Vasconcelos, 2002), ao longo do século passado, apontam para o início na década de 1940, e essa origem é marcada por uma formação que permitia tanto atuação clínica (dietoterapia) quanto institucional, voltada aos serviços de alimentação dos trabalhadores vinculados à Previdência Social, no contexto econômico político que marcou a primeira metade do século passado. $\mathrm{O}$ contexto do pós-guerra trouxe preocupação com a alimentação em escala planetária, favorecendo, portanto, o desenvolvimento da profissão. No Brasil, esse crescimento se efetivou com a ampliação dos cursos, com seu reconhecimento como curso de nível superior e com a aprovação da lei de regulamentação da profissão no final da década de 1970, bem como com a criação dos conselhos federal e regionais 
da categoria, que, até então, funcionavam sob a responsabilidade dos órgãos regionais de fiscalização da medicina.

Outras pesquisas realizadas nos últimos anos sobre o papel do nutricionista na atenção básica tomam como referência o cenário de transição epidemiológica (Ferreira e Magalhães) e alegam a relevância dos serviços de atenção básica no que diz respeito à Política Nacional de Alimentação e Nutrição (PNAN) (Brasil, 2013), não se podendo prescindir do nutricionista. Nesses estudos, há alguma problematização acerca da importância das ações de promoção de saúde no que se refere à alimentação e à nutrição, bem como à defesa da contribuição do nutricionista nesse processo. Entretanto, ainda não temos a clareza dos desafios que esse cenário de transição epidemiológica exige da nutrição em termos de organização de seus serviços no âmbito da atenção básica, pois essa questão, com frequência, é apenas tangenciada nas discussões.

Marcado historicamente por uma formação eminentemente clínica, atualmente o campo da nutrição enfrenta muitos desafios, no sentido de dar respostas aos problemas que surgem em função da transição epidemiológica e do rápido avanço das doenças crônicas em suas relações com as práticas alimentares e repercussões sobre a saúde pública. Pádua e Boog (2006) demonstraram que, hoje, as funções exercidas pelo nutricionista na ESF têm-se concentrado, prioritariamente, em prescrições e orientações dietoterápicas, acrescidas de palestras para grupos, visitas domiciliares, campanhas e colaboração nos programas de alimentação e nutrição. Em função disso, cabe refletir até que ponto essas ações, sobretudo a prescrição dietoterápica, têm colaborado como uma intervenção eficaz para fazer frente aos desafios do cenário epidemiológico atual.

Neste estudo, não pretendemos defender a importância do nutricionista para a atenção básica do SUS ou apontar eventuais lacunas em seu atuar nesse campo. Nosso intuito é problematizar os desafios com que a categoria depara, na tentativa de organizar seu processo de trabalho, como parte de uma equipe multiprofissional, focalizando um Centro de Saúde da Família (CSF), de modo a refletirmos sobre os limites e as possibilidades que se impõem à prática dos nutricionistas no âmbito da atenção básica do SUS. Cabe salientar que tais reflexôes advêm de uma experiência de trabalho com a formação de nutricionistas residentes que atuam no CSF de Sobral, município do Ceará, nordeste do Brasil, vinculados à Residência Multiprofissional em 
Saúde da Família, promovida pela Escola de Formação em Saúde da Família Visconde de Saboia, localizada em Sobral.

\section{Contextualizando o problema}

A inserção do nutricionista na ESF em Sobral teve início em 2003, com a Residência Multiprofissional em Saúde da Família (RMSF) (Martins Jr. et al., 2008), implantada como estratégia para enfrentar o desafio de se reorganizar o modelo de atenção à saúde municipal a partir da qualificação dos profissionais do sistema. Desde então, a experiência de cerca de uma década de trabalho com equipes multidisciplinares na atenção primária do município tem proporcionado importantes reflexōes acerca do processo de inserção de várias categorias profissionais na ESF, tornando-se possível acumular uma rica experiência de trabalho multidisciplinar.

No período de 2008 a 2010, o município de Sobral contava com 11 nutricionistas que atuavam na atenção básica, sendo seis residentes e cinco integrantes das equipes dos NASF. Os nutricionistas residentes também integravam as equipes multidisciplinares, as quais se responsabilizavam por dois territórios da sede do município. As equipes multidisciplinares de residência em Saúde da Família eram compostas pelos seguintes profissionais: psicólogo, nutricionista, farmacêutico, educador físico, fonoaudiólogo, assistente social, enfermeiro e dentista.

A formação a que se refere o estudo é a Residência Multiprofissional em Saúde da Família, que não inclui médicos. Os médicos que optam pela atenção básica podem fazer residência em Medicina de Família e Comunidade. No cenário analisado, os médicos estão presentes no CSF como integrantes da equipe mínima.

$\mathrm{O}$ processo de inserção da equipe multidisciplinar de residentes na ESF de Sobral acontece por meio da territorialização (Dias e Dias, 2010). Em resumo, refere-se a um conjunto de atividades que envolvem toda a equipe (residentes, tutores, preceptores e profissionais do serviço), com o objetivo de proporcionar a apropriação do território, bem como de compreender o funcionamento do Centro de Saúde da Família e a dinâmica viva do território no qual a equipe irá atuar. Os residentes desenvolvem atividades de observação participante e de investigação, buscando compreender o modo como a população vive e produz formas de viver saudável e de adoecimento 
que caracterizam os processos de saúde e doença. Outro aspecto importante consiste em apreender como a população se relaciona com os equipamentos sociais existentes, sobretudo o CSF, e como este se organiza para atender às necessidades de saúde da população daquele território.

Assim, a partir da territorialização, cada categoria profissional, em conjunto com a tutoria e a preceptoria, planeja a organização de seu serviço, buscando atender às necessidades de saúde até então percebidas. Em relação à nutrição, optou-se inicialmente por organizar a agenda destinando, em média, um turno para cada tipo de atividade em cada um dos territórios: atendimento ambulatorial, visita domiciliar, ações coletivas e colaboração com a organização e o funcionamento cotidiano do CSF. Como se tratava de uma formação em serviço, a agenda ainda previa atividades pedagógicas em equipe multiprofissional e outras por cada categoria profissional.

Em parceria com os profissionais, elencamos critérios para a atuação da equipe multiprofissional, acordando, inclusive, que o encaminhamento dos usuários aos residentes deveria ser feito pelos profissionais da equipe básica (médico, enfermeiros, agentes comunitários de saúde e demais profissionais da equipe multiprofissional). Esse critério teve por objetivo potencializar a atuação do nutricionista. Acreditávamos que essa decisão organizaria os atendimentos a partir do encaminhamento das demandas que mais exigiam cuidados específicos da clínica de nutrição.

A partir dessa organização inicial, o cotidiano de trabalho no território nos trouxe grandes desafios e indagações. A agenda de trabalho dos nutricionistas, apesar de o território contar com dois profissionais, apresentava uma demanda muito grande para o atendimento clínico, apesar de o CSF contar com a atuação de dois nutricionistas - um como residente em Saúde da Família e outro como integrante da equipe do NASF. Assim, ao longo do primeiro ano, houve necessidade de modificarmos a agenda, destinando mais turnos para esse fim e diminuindo o número de visitas domiciliares. Porém, mesmo com essa modificação, dia após dia, havia aumento exponencial da demanda para consultas clínicas no âmbito da terapia nutricional.

O desafio, portanto, consistia em compreendermos mais profundamente tal fenômeno. Optamos, então, por fazer um estudo sobre essa demanda, passando a inserir nos relatórios mensais das atividades desenvolvidas pela equipe da RMSF anotações sobre quem demandava e os motivos do encaminhamento de usuários aos nutricionistas, ou seja, queríamos 
identificar quais profissionais, tanto da equipe mínima como da multiprofissional, realizavam o encaminhamento e quais critérios eram adotados. Concluímos, então, que alguns pacientes estavam agendando consulta com a nutricionista por meio dos profissionais do Sistema de Arquivo Médico e Estatística (SAME), ${ }^{3}$ sem que fossem encaminhados por profissionais da equipe mínima, que era um dos critérios previamente estabelecidos. Constatamos também que, mesmo que destinássemos toda a agenda da nutrição para esses atendimentos, não seria possível dar conta da demanda. Mesmo com a presença de dois nutricionistas atuando no mesmo CSF, a espera por atendimento era de três meses, em média.

Era notória a ausência de nutricionistas em outras atividades de atenção primária, como, por exemplo, acompanhamento de grupos específicos (idosos, adolescentes, gestantes), visitas domiciliares e colaboração nos programas de alimentação e nutrição. Havia uma demanda silenciosa e silenciada, representada pela população de hipertensos e portadores de diabetes. Entre os diabéticos, inclusive, havia pessoas dependentes de insulina e com diversas complicaçôes; percebíamos tratar-se de casos que demandavam maior atenção, a fim de evitar danos mais graves à saúde. Havia a necessidade silenciada da presença de um nutricionista no acompanhamento pré-natal e na puericultura. Sentíamos que, uma vez quebrado esse padrão pela modificação na rotina do CSF, seria possível diminuir, de forma significativa, a demanda por atendimento clínico de nutrição.

A realidade nos trazia uma questão pulsante: como organizar o serviço de nutrição em um CSF cuja agenda não fosse engolida pela demanda clínica? Observávamos demandas silenciadas e nos perguntávamos por que só a clínica tinha vez e voz para a agenda de nutrição no funcionamento do CSF. Como propor outro processo de organização do serviço se o gerenciamento do CSF não se dava conta disso e, portanto, não demandava a intervenção de nutricionistas nos serviços citados? Percebíamos que havia demanda da população, já que os usuários chegavam à clínica sem passar por encaminhamento da equipe mínima. Observávamos problemas no gerenciamento dos serviços no CSF, que direcionava o trabalho e a agenda dos profissionais da equipe

3 O SAME é um setor que organiza a agenda dos profissionais da atenção básica e programa as consultas de acordo com o encaminhamento dos profissionais. O agendamento para os profissionais do NASF e da Residência sempre deve partir do encaminhamento de outro profissional que identifique a necessidade da consulta. 
multiprofissional somente para a demanda clínica, sem sequer questioná-la. A clínica é a única demanda que os profissionais fazem ao nutricionista na atenção básica, esse é o cerne do problema!

Era preciso, então, analisar essa alta demanda na clínica do nutricionista, verificando quem demandava e por que demandava sem questionamento. Verificou-se que até o SAME (setor que organiza a agenda dos profissionais) estava realizando a demanda a partir dos desejos da população, sem passar por outros profissionais, como previamente acordado. Isso demonstra que até a população estava demandando consulta, o que dificultava o gerenciamento dos serviços da equipe multiprofissional na ESF. Tal cenário trazia um sentimento de impotência e, para tentar modificar essa realidade, precisávamos compreender mais profundamente os desafios na organização do processo de trabalho do nutricionista no CSF.

\section{Percurso metodológico}

Este estudo caracteriza-se como uma abordagem qualitativa (Minayo, 1996), justificada pela própria natureza da questão investigada, que exige o desvelar do fenômeno, aprofundando-se em sua compreensão. O estudo foi desenvolvido em um CSF da sede de Sobral e envolveu profissionais da equipe mínima e residentes de nutrição. O estudo foi realizado por ocasião da formação em Residência Profissional em Saúde da Família, promovida pela Escola de Formação em Saúde da Família Visconde de Saboia.

$\mathrm{O}$ trabalho de pesquisa foi desenvolvido em duas etapas. Na primeira, recorremos à técnica de análise de documentos, com o objetivo de conhecer e caracterizar as demandas encaminhadas ao nutricionista no CSF. Houve levantamento e análise dos mapas de atendimento diário relativos ao período de um ano. Também foram analisados os relatórios mensais da agenda de trabalho do nutricionista residente, que atuava em dois territórios da sede do município.

A segunda etapa teve por finalidade conhecer os limites e as possibilidades da atuação do nutricionista na atenção básica. Segundo as análises oriundas da primeira etapa, identificamos que os enfermeiros e os agentes comunitários de saúde (ACS) eram os profissionais que mais encaminhavam para a clínica de nutrição. Em seguida, empregamos duas técnicas para a apreensão de material empírico: a primeira, com os grupos focais - en- 
fermeiros e ACS. O objetivo era apreender a percepção desses profissionais sobre o processo de trabalho do nutricionista na ESF e conhecer os motivos que levavam esses profissionais a encaminharem os pacientes ao atendimento clínico do nutricionista. A segunda técnica empregada nessa etapa foi a aplicação de um questionário aberto aos nutricionistas da Residência Multiprofissional em Saúde da Família, incluindo todos os profissionais residentes atuantes nos CSF da sede de Sobral, com o objetivo de captar as divergências e as semelhanças nos processos de organização do serviço de nutrição em outros territórios.

Por fim, procedeu-se a uma exaustiva leitura do material empírico oriundo da transcrição das falas dos sujeitos da pesquisa, no intuito de apreender o "todo" das falas presentes nos grupos focais e nos questionários. Reconhecemos, na análise do discurso, uma ferramenta que permite a apreensão das unidades de sentido que se delineiam no material empírico. Como esclarece Orlandi (2000), trata-se não apenas de captar os discursos, numa perspectiva de desvelar ou traduzir, mas também de apreender uma produção de sentido revelada no vetor sensível da linguagem expressa no universo semântico dos sujeitos implicados.

Todos os participantes dos grupos focais e também aqueles que responderam ao questionário passaram por um processo de esclarecimento sobre a pesquisa, por meio da assinatura de um Termo de Consentimento Livre Esclarecido e de um Termo de Consentimento Pós-Informado, conforme recomenda a Resolução no 196/96 do Conselho Nacional de Saúde/Ministério da Saúde (Brasil, 1996) sobre pesquisas que envolvem seres humanos. Esse documentos foram assinados em duas vias, ficando uma com o sujeito/ participante e outra com a pesquisadora.

\section{Resultados e discussão}

O foco central desta pesquisa foram os encaminhamentos realizados ao nutricionista pela equipe mínima do CSF e a compreensão, com maior profundidade, dos desafios enfrentados por esse profissional no âmbito da atenção primária. Dois motivos justificaram o estudo.

O primeiro, porque a ação se destacou de forma predominante em sua agenda, com as equipes de enfermagem e de ACS compondo os profissionais que mais encaminhavam pacientes. 
O segundo, porque, ao compreendermos a dimensão simbólica subjacente à ação humana, sempre carregada de significados, consideramos possível, mediante a respectiva análise, desvelar o papel que o nutricionista vem assumindo no CSF para além dos discursos dos profissionais de saúde, ou seja, nosso intuito era confrontar ideias e ações para a melhor compreensão de nosso objeto.

Nesse sentido, iniciamos o estudo pela análise do relatório mensal de trabalho da nutrição, que registrou as seguintes atividades: atendimento clínico; visitas domiciliares; acompanhamento de grupos e atividades relacionadas à colaboração na organização de serviços como acolhimento e educação em saúde. A análise nos mostra uma média mensal de três visitas domiciliares, acompanhamento sistemático de um grupo e uma média de 19 atendimentos na clínica, bem como colaboração esporádica no acolhimento do CSF.

Analisamos também o mapa diário dos atendimentos clínicos do nutricionista residente de um CSF no período de um ano e obtivemos o seguinte resultado:

Tabela 1. Proveniência da demanda dos atendimentos individuais (CSF/Sobral - set. 08-set. 09)

\begin{tabular}{|l|c|c|c|c|c|}
\hline $\begin{array}{l}\text { Proveniência } \\
\text { da demanda }\end{array}$ & $\begin{array}{c}\text { Equipe } \\
\text { Mínima }\end{array}$ & $\begin{array}{c}\text { Equipe Multi- } \\
\text { profissional }\end{array}$ & Usuário & Sem registro & TOTAL \\
\hline Percentual (\%) & 54,39 & 14,04 & 17,53 & 15,04 & 100 \\
\hline
\end{tabular}

Tabela 2. Distribuiçãao dos atendimentos individuais por ciclo de vida (CSF/Sobral - set. 08-set. 09)

\begin{tabular}{|l|c|c|c|c|c|c|}
\hline Ciclo de vida & Criança & Adolescente & Adulto & Gestante & Idoso & TOTAL \\
\hline Percentual (\%) & 20,56 & 12,15 & 46,73 & 11,21 & 9,35 & 1100 \\
\hline
\end{tabular}

Constatamos que a maioria dos encaminhamentos provém dos profissionais da equipe mínima (54,39\%). Todavia, o que chamou a atenção foi a demanda parte dos próprios usuários (17,53\%). Observamos que havia um número expressivo de usuários que marcavam consultas diretamente com os profissionais do SAME. Organizando os atendimentos por ciclos de vida, percebemos a população adulta (20 a 59 anos) representando praticamente 
a metade do total de casos atendidos (quase 50\%), seguida da população infantil $(20,56 \%)$.

Em todos os ciclos de vida, o encaminhamento foi relacionado a obesidade e sobrepeso, à exceção das crianças. Esse fato acentuou-se na população adulta, em que $61 \%$ dos casos encaminhados estavam relacionados à obesidade. Os casos de hipertensão arterial e/ou de diabetes mellitus atingiram 24,68\%. Quanto às crianças, desnutrição e baixo peso representavam aproximadamente $45 \%$ dos casos; no entanto, excesso de peso (sobrepeso e obesidade) representou quase $30 \%$ dos casos.

Tabela 3. Distribuição dos tipos de atendimento por ciclo de vida (CSF/Sobral, set. 08-set. 09)

\begin{tabular}{|l|c|c|c|c|}
\hline $\begin{array}{l}\text { Ciclo de vida } \\
\text { Demanda }\end{array}$ & Adolescente & Adulto & Gestante & Idoso \\
\hline $\begin{array}{l}\text { Baixo peso e/ou } \\
\text { desnutrição }\end{array}$ & 7,14 & 1,30 & 10,00 & 4,35 \\
\hline Sobrepeso & 21,43 & 14,29 & 50,00 & 4,35 \\
\hline Obesidade & 50,00 & 46,75 & 10,00 & 30,42 \\
\hline $\begin{array}{l}\text { Hipertensão e } \\
\text { diabetes }\end{array}$ & - & 24,68 & - & 39,13 \\
\hline Dislipidemia & - & 7,79 & - & 8,70 \\
\hline Outros & 21,43 & 5,19 & 30,0 & 105 \\
\hline
\end{tabular}

Tabela 4. Distribuição dos tipos de atendimento por ciclo de vida: crianças (CSF/Sobral - set. 08-set. 09)

\begin{tabular}{|l|c|}
\hline Tipo de Atendimento & Percentual (\%) \\
\hline Desnutrição e/ou baixo peso & 45,83 \\
\hline Risco nutricional & 8,33 \\
\hline Sobrepeso & 12,50 \\
\hline Obesidade & 16,67 \\
\hline Outros & 16,67 \\
\hline TOTAL & 100 \\
\hline
\end{tabular}


A análise desses registros mostra que o fazer da nutrição tem-se efetivado na ESF em função de uma demanda essencialmente clínica relacionada à prescrição dietoterápica que tem por foco a obesidade. Essa realidade também estava sendo vivenciada pelos profissionais de outros CSF, segundo a análise das respostas ao questionário aplicado aos nutricionistas residentes que integravam as equipes dos territórios da sede do município. Esses profissionais responderam a perguntas sobre a organização de seu processo de trabalho, com foco no atendimento clínico, investigando os autores e os motivos da demanda, se concordavam ou não com os encaminhamentos feitos e de que forma os demais profissionais percebiam o serviço de nutrição em seu CSF.

De acordo com as respostas dos nutricionistas, a maior parte da demanda para atendimento clínico em seus territórios também proveninha da equipe mínima: médicos, enfermeiros, com um número mais expressivo de agentes comunitários de saúde. Havia também a chamada "demanda espontânea", ou seja, os usuários que marcavam consulta diretamente no balcão do SAME. A motivação para os encaminhamentos também estava relacionada a excesso de peso (sobrepeso e obesidade), com ênfase para adultos, adolescentes e gestantes, sendo também mencionados, embora com menor incidência, os de pessoas com hipertensão arterial e diabetes mellitus.

A análise desses questionários nos mostra que há consenso geral de que o nutricionista é um profissional cujo processo de trabalho é clínico e que está no CSF para fazer atendimento clínico ambulatorial. É comum esse profissional ser alvo de reclamação por parte de outros profissionais sobre sua ausência em atividades relacionadas aos grupos e aos programas de alimentação e nutrição. Por outro lado, mesmo quando o nutricionista tenta envolver-se nessas atividades, ainda é alvo de crítica por parte dos profissionais do CSF, apenas com alteração no enfoque, passando a ser visto como ocioso. Isso porque o envolvimento em atividades diversas daquelas que são próprias da terapia nutricional é interpretado como um esquivar-se de atender no consultório individual.

É comum a gerência do CSF comparar a produtividade entre a clínica de nutrição e a de enfermagem, reclamando que o nutricionista quer atender apenas quatro pessoas numa manhã, enquanto o enfermeiro atende 16 . Ninguém se questiona acerca da natureza e da especificidade do atendimento efetuado por esses profissionais, o tempo necessário ou o objeto da prática. 
Ao que parece, o foco se volta apenas para a produtividade, entendida como o número de atendimentos.

Pelos relatos que se seguem, é possível perceber a inexistência de consenso entre os profissionais das equipes mínima e multiprofissional sobre o que é prioridade para a clínica de nutrição. Cada CSF organiza, à sua maneira, os processos de trabalho do nutricionista para dar conta da demanda.

[...] quando eu [nutricionista residente] falava que o número máximo de atendimentos por turno eram quatro, indagavam como eu atendia apenas quatro se o enfermeiro atende $16 \mathrm{em}$ um turno!

Acho que o que precisamos é de maior interação com os profissionais da equipe mínima, ampliando a percepção acerca do potencial de ação do nutricionista. Chegou uma fase do meu processo de trabalho em que eu era conhecida como "a mulher que emagrece o povo".

[...] só o nutricionista não é suficiente em questôes que envolvem, por exemplo, a obesidade, a qual é uma síndrome multifatorial, e faz-se necessário um empoderamento de varias categorias profissionais.

É unânime entre os profissionais da nutrição a referência ao excesso de demanda clínica em todos os CSF, sendo essa demanda percebida como obstáculo para a diversificação de suas atividades. No entanto, se há pressão por mais atendimento clínico do nutricionista proveniente dos profissionais da equipe mínima, a pressão do movimento contrário também se faz presente. Alguns nutricionistas, em suas respostas, sugeriram mudança no processo de trabalho relacionada apenas à melhor adequação dos encaminhamentos, citando, por exemplo, que o encaminhamento de mulheres já no terceiro trimestre de gestação ou quando já apresentam sobrepeso é inadequado. Outras respostas argumentam que, embora os demais profissionais também saibam indicar alimentos menos calóricos, é o nutricionista que detém o saber sobre alimentação saudável, cabendo-lhe, inclusive no plano legal, a prescrição dietoterápica.

O cotidiano nos revela que, com frequência, os nutricionistas absorvem demandas sem questionar os processos de trabalho na atenção básica, seja para atender a expectativas relacionadas à nutrição por parte dos demais 
membros da equipe, seja para permanecer apenas em seu espaço clínico de atuação, no qual se sente mais capacitado a atuar. Segundo Cunha (2005), o conhecimento da Biomedicina ainda é hegemônico na clínica dos diversos profissionais e se mostra insuficiente na atenção básica, por não incluir a singularidade dos sujeitos e os limites da terapêutica quando não se tem o hospital como referência, e sim o território vivo.

Esse fato converge para o estudo realizado por Boog (2008) ao abordar a competência para a promoção de práticas alimentares saudáveis com a inserção do nutricionista na rede básica de saúde, representando uma referência para o trabalho em equipe. Boog ressalta uma queixa comum entre os nutricionistas sobre a desvalorização de seu trabalho na equipe, apontando para a necessidade de se superarem alguns obstáculos para o bom desempenho coletivo. Com um estudo embasado nas proposições de Berger e Luckmann, concernentes à construção social da realidade, Boog operacionaliza o conceito desses autores sobre tipificação social com vistas a compreender os obstáculos para se realizar um trabalho em equipe. Segundo ela, as pessoas constroem uma tipificação social para as profissões que dificilmente coincide com o perfil de quem chega para desempenhar esse papel numa equipe. Acrescenta que as pessoas, de modo geral, tendem a exercer sua profissão levando muito mais em conta o que os outros dizem que devem fazer do que aquilo que está em consonância com sua formação. Essa análise contribui para esclarecer o impasse vivido pelos nutricionistas residentes e sugere que ainda há um longo caminho a percorrer no que concerne à atuação da categoria no campo da atenção básica em saúde.

Outro ponto de problematização diz respeito ao funcionamento do CSF. Seria a demanda concentrada na clínica de nutrição induzida pelo modelo de cuidado do CSF ou seu gerenciamento estaria apenas canalizando a necessidade social nessa esfera de prática? Há um gerenciamento com base em produtividade que torna homogênea a atuação de todos da equipe, constituindo-se em uma espécie de anteparo para que se vejam as diferenças do espaço clínico em cada categoria. Também constatou-se um percentual significativo de demanda clínica oriundo de pessoas que marcavam consulta diretamente no balcão do SAME. O que contribui para essa realidade tanto no fazer/pensar dos profissionais da saúde como da população, a qual, como observado, também reivindicava atendimento clínico da nutrição? De que forma o profissional pode lidar com esse contexto e articular essa realidade do território? E como lidar com o gerenciamento em seus processos de trabalho no CSF? 
É preciso haver um aprofundamento crítico acerca dos serviços na atenção básica. Conforme preconizado pela Política Nacional de Atenção Básica (2006), os serviços devem organizar-se de modo a atender às necessidades de saúde do território. Até que ponto organizar o processo de trabalho em função da necessidade do território implica direcionar o atendimento para dar conta da demanda clínica? Até que ponto a demanda clínica daquele território era legítima em termos de efetivação da atenção básica no sentido de promoção da saúde? Organizar o serviço concentrando-se em prescriçôes dietoterápicas seria a melhor forma de organizar o serviço para atender essa população? A expressão da necessidade de saúde relacionada à nutrição e direcionada para clínica não a deve ser absorvida sem um pensar crítico, trazendo questôes que demandam reflexão e respostas.

Quando da análise, verificou-se que o fato de um saber específico estar relacionado a prescrições dietoterápicas é a base para a construção dos argumentos favoráveis à inserção do nutricionista na ESF. Ficou claro que a demanda por prescrição de dieta é oriunda dos profissionais da equipe mínima da ESF, da população adscrita e do próprio profissional da nutrição. Não é nossa intenção aqui retirar a importância desse serviço, mas tão somente refletir a respeito desse fenômeno, de modo a aprofundar sua compreensão.

Nesse contexto, constatamos que um ponto nevrálgico para o nutricionista nesse campo consiste em encontrar saídas que não reduzam seu fazer a isso! Essa questão é relevante porque representa a porta de entrada reivindicada pela categoria para atuar na atenção básica, além de convergir para uma demanda da população e dos profissionais da ESF. Há uma forte pressão por esse enquadramento, o que torna difícil contorná-lo, levando em conta a expectativa de vários segmentos ao fazer do nutricionista.

Nosso foco de atenção concentrou-se nos encaminhamentos realizados pela equipe mínima (enfermeiras e ACS) ao serviço de nutrição. Organizamos a fala desses sujeitos nas seguintes categorias: expectativas da equipe mínima quanto à inserção do nutricionista na ESF; percepção sobre a organização do processo de trabalho da nutrição no CSF; e os motivos pelos quais encaminham usuários para o atendimento clínico da nutrição.

A expectativa dos enfermeiros em relação ao nutricionista se expressa pela divisão de tarefas: complementando um fazer específico relacionado à dieta ou aliviando uma sobrecarga existente. A fala seguinte ilustra bem esse aspecto: 
[...] A inserção do nutricionista dentro do Saúde da Família veio tirar uma sobrecarga muito grande da enfermagem [...], "aliviando" o profissional enfermeiro [...], dando complemento muitas vezes a uma conduta nossa (G2).

Não se mencionou a possibilidade de imprimir maior qualidade ao atendimento, em termos de integralidade, com a chegada desse novo profissional. Consoante Mattos (2003), a integralidade assume sentidos distintos, que incluem a atitude dos profissionais de saúde com vistas a compreender a necessidade, por parte do usuário, de um conjunto de ações e serviços de saúde; os modos de organizar os serviços de saúde e o plano das políticas de saúde. A integralidade na prática, como uma manifestação da prestação de cuidados, implica que se reconheça a intersubjetividade na definição dos projetos terapêuticos, processo no qual as categorias distintas devem ser reconhecidas e adequadamente inseridas. Contudo, no espaço analisado, a compreensão da parceria ocorre no sentido da complementação de saber, e a nutrição é encarada como uma especialidade destinada a quem pode pagar pelo serviço. Assim, o acesso ao nutricionista é entendido como um privilégio para a população pobre, como bem ilustra esta fala do grupo de enfermagem:

[...] o pessoal chega aqui querendo uma consulta com o nutricionista, né, um atendimento especializado [...] a grande maioria das pessoas que buscam o serviço são pessoas que têm um baixo poder aquisitivo, que não poderiam pagar um nutricionista em outro local. (G2)

Essa visão de um serviço como privilégio é corroborada por outras pesquisas, como, por exemplo, os estudos realizados por Santos (2005) e Boog (2008), que afirmam algo semelhante quanto à visão, por outros profissionais da equipe, do nutricionista como um artigo de luxo.

O agente comunitário de saúde, cujo serviço está essencialmente ligado à educação em saúde, é o profissional que percebe, com mais facilidade, o fazer do nutricionista relacionado à reeducação alimentar, como retrata esta fala do grupo:

[...] quando a nutricionista vem, [...] vem com um propósito de mudar o hábito alimentar [...] tanto faz o obeso, o desnutrido, o hipertenso, o diabé- 
tico, [...] ela vem com o propósito de mudar o hábito alimentar que nossa comunidade não tem! (G1)

Embora o ACS aponte a reeducação alimentar como principal fazer da categoria, essa tarefa é percebida em função de a clínica ser direcionada, prioritariamente, para a população que apresenta alguma patologia. Um destaque interessante nessa fala é a capacidade de o nutricionista mudar o hábito alimentar da comunidade, sobretudo da população com diabetes e hipertensão. O "hábito alimentar que nossa comunidade não tem" sugere a compreensão de que a comunidade alimenta-se de forma errada e cabe ao nutricionista, quando chega, consertar isso, prevenindo eventuais doenças. A visão do ACS sobre o fazer da nutrição sugere, portanto, uma crença (que não é só deles) de que o nutricionista detém o saber, o poder e a responsabilidade de mudar o padrão alimentar da comunidade.

A percepção da equipe mínima relacionada à organização do processo de trabalho da nutrição no CSF mostra que há um reconhecimento, tanto por parte dos ACS como dos enfermeiros, acerca da necessidade de se ampliarem as atividades do nutricionista, destacando os trabalhos educativos realizados com grupos, capacitação no tema "alimentação e nutrição saudável” e parceria com os demais profissionais. Entretanto, quando indagamos a forma de melhor organizar essas atividades na agenda da nutrição, ambas as categorias profissionais apontaram para o excesso de demanda clínica como um obstáculo para se ampliar e aperfeiçoar o fazer da nutrição no CSF. Os ACS declararam que o obstáculo para essa ampliação reside na falta de tempo do profissional. Segundo eles, deveria haver mais nutricionistas, pois a demanda de atendimento no CSF é grande e não sobra tempo para visitas domiciliares ou para a realização de atividades na comunidade. Destacaram também a rotatividade dos profissionais no serviço e a demora no retorno das consultas.

[...] tem retornos que demoram, que demoram muito. [...] Não concordo com a organização porque você não vai saber como dar conta da demanda, que é tão grande [...] aquela história de um nutricionista ficar aqui um mês, dois meses, aí no outro mês já ser outra pessoa [...] aí complica muito, não dá continuidade. (G1) 
Os enfermeiros apontam o excesso de demanda como o principal obstáculo para aperfeiçoar o processo de trabalho do nutricionista no CSF, ressaltando o número insuficiente de profissionais dessa área para atender a população adscrita da equipe do CSF. O ponto interessante é que, para ambas as categorias, a saída para esse impasse estaria na ampliação do número de nutricionistas, ou seja, não há uma reflexão crítica sobre o que gera essa demanda excessiva e se o atendimento clínico é realmente a resposta para esse problema.

Entretanto, um aspecto interessante mencionado pelos ACS em relação à sua percepção sobre a organização do processo de trabalho da nutrição no CSF foi a necessidade de se adequar a prescrição ao contexto comunitário, no sentido de dietas que estejam em consonância com a renda da família. Eles relatam casos de usuários que não sabiam onde comprar os alimentos listados nas dietas. Cabe salientar que essa adequação na prescrição não está atrelada apenas à condição financeira da família, mas também ao seu modo de vida, como ressaltado a seguir:

[...] quando a gente fala em desnutrição, a gente imagina aquela família bem pobrezinha, passa fome mesmo. Já aconteceu um caso, por exemplo, na minha área, que a criança era desnutrida, mas pai e mãe trabalham, têm casa própria, transporte, quer dizer, eles têm condição de alimentar aquela criança da maneira correta; só que não alimentam muitas vezes por falta de informação, uma orientação. [...] É importante a questão da reeducação, o nutricionista pra estar reeducando essas pessoas, porque às vezes não é questão da família ser pobre, não ter o que comer [...]. (G1).

Esse aspecto é interessante porque traz uma visão crítica do fazer da categoria. Porém, é inegável o sentido de que a melhoria permanece atrelada ao fazer da clínica. É importante indagarmos se realmente o problema seria resolvido com a adequação da prescrição às condições de renda da família. Ou seja, seria somente essa inadequação a causa do não seguimento da dieta? Por outro lado, a educação em saúde é reduzida ao repasse de informações. Seria apenas a oferta de informação ou orientação adequadas que resolveria o problema da desnutrição no contexto familiar e comunitário a que se refere o ACS?

Essa ideia foi reforçada em outras falas dos ACS, que aludem à crença de que a simples presença do nutricionista, seja no grupo ou no domicílio, 
é capaz de fazer as pessoas seguirem prescrições. Mesmo que tais prescrições se mostrem contrárias às rotinas e aos hábitos alimentares, solicita-se a visita domiciliar, na esperança de que o nutricionista possa adequar a dieta da família ou desenvolver alguma atividade que resulte na mudança do comportamento alimentar. Até mesmo os encaminhamentos realizados para a clínica são feitos com base nessa ideia: que a consulta com o nutricionista modifique comportamentos. Esse aspecto evidencia uma leitura alinhada ao modelo biomédico, segundo o qual a subjetividade se exclui na análise dos hábitos e comportamentos, reduzindo a prática à sua dimensão técnica.

Há um entendimento geral de que quem prescreve deve assumir a responsabilidade por seu seguimento e a crença de que o cumprimento da dieta depende apenas de monitoramento. A dieta passa a ser vista quase como uma medicalização, uma vez que seu descumprimento causa complicação nas pessoas que têm hipertensão e diabetes, tornando o ato de se alimentar um "medicalizar-se". Isso fica claro quando os ACS falam da necessidade da visita do nutricionista para obrigar as pessoas a seguirem a dieta, por meio de monitoramento contínuo, significado muito presente na seguinte fala:

[...] Tem que ter o nutricionista, tem que monitorar. Se você der uma dieta pro paciente aqui no posto, quando ele chegar em casa, não vai fazer a dieta, vai fazer o oposto [...]. Pra ter uma ideia, eu visitei uma hipertensa e diabética ontem. Adivinha o que ela tava comendo quando eu cheguei? Rapadura! Ela tava comendo feijão com osso de boi dentro, tripa, arroz, macarrão, depois comeu doce, comeu manga e um monte de coisa, durante a visita. Aí eu perguntei: "Qual é a dieta que você faz? Cadê a dieta que a nutricionista passou?" “Tá guardada lá dentro da bolsa, vou fazer é meu 'buchão’ Ah! se eu vou morrer de fome?! [...]". O nutricionista tem que estar mais perto do paciente, tem que acompanhar [...], acompanhar três meses, quatro meses, o paciente. Você não vai acompanhar o resto que vai ser necessário pra ele. (G1)

Essa fala de usuário da comunidade nos faz refletir que a mudança de hábito alimentar, como ocorre em relação a qualquer hábito, é algo ainda muito opaco, que exige estudo e pesquisa. Envolve uma complexa articulação entre padróes culturais, familiares e de paladar, bem como de adequação ao modo de vida das pessoas, acesso a alimentos e propaganda da mídia associada à indústria e ao comércio de alimentos e até mesmo o tempo necessário, 
como bem ressalta o ACS. Embora se reconheça a necessidade de haver reeducação alimentar, essa responsabilidade não deve ser apenas de um profissional da ESF, mas de todos, inclusive dos usuários.

Outra dimensão investigada foram os motivos que levam ao encaminhamento para a clínica de nutrição pelos ACS e enfermeiras. Ambos declararam encaminhar pessoas com diabetes, hipertensão, gestantes e crianças desnutridas e obesas. Quando se trata de obesidade, o critério referido por ambos os grupos foi o desejo de emagrecer por parte do usuário. Porém, o que mais chamou a atenção foi a forma difusa com que elaboram os critérios para encaminhamento. Na fala do grupo de enfermeiros, destacamos o seguinte:

[...] Eu acho que não existe critério maior do que pensar no crescimento e desenvolvimento saudável dessa pessoa. [...] Os critérios são basicamente estes: manter nutrido, estar saudável, permanecer saudável, crescer e se desenvolver saudável. (G2)

Quanto aos ACS, os critérios permanecem difusos. Eles sentem a necessidade de utilizar algum instrumento que ajude na decisão, assegurando que a pessoa está fora do padrão normal de IMC (Índice de Massa Corporal), abaixo ou acima do peso, algo semelhante ao trabalho antropométrico que realizam com as crianças. É o que destaca a fala do grupo:

[...] Os critérios utilizados para encaminhar pro nutricionista: primeiro, é o "olhômetro", porque a gente não tem nenhum instrumento que meça com frequência a altura e o peso [...]. Sempre, numa família ou noutra, existe uma necessidade, é o pai, o filho, aquela criança, aquela gestante, o idoso ou o sobrinho, mas sempre tem um que precisa realmente estar tendo aquilo que já discutimos aqui, a educação alimentar, que está precisando do nutricionista, de informaçōes [...]. (G1)

Os motivos apresentados pela equipe mínima para o encaminhamento ao nutricionista merecem reflexão. Não se nega a importância do desejo de emagrecer como um critério importante, mas é preciso indagar: qual o papel da equipe mínima nesse caso? Seria apenas o de mediador entre a população e o nutricionista? Como equacionar isso dentro da atenção básica? Como organizar os serviços de atenção com base nas necessidades de saúde 
do território se for efetivada a inversão do modelo de atenção baseado na promoção de saúde?

Por outro lado, é preciso pensar também nas "ausências" que esses encaminhamentos revelam. Não há encaminhamento ou solicitação por parte dos profissionais da equipe mínima quanto a grupos de hipertensos ou diabéticos, ou mesmo para uma atuação conjunta em puericultura. Até mesmo o encaminhamento de gestantes fica reservado àquelas que estão acima do peso, sem que se tenha como foco um pré-natal que mereça integralidade na atenção. Ainda que a atividade referida seja uma visita domiciliar ou uma atividade ligada à educação em saúde, esses profissionais entendem que o nutricionista deve ter como foco o seguimento da prescrição da dieta.

Embora se reconheça a necessidade de se realizarem outras atividades, o núcleo de sentido presente nos discursos e nas ações dos profissionais da equipe mínima deixou claro que o papel da nutrição na ESF é concebido como algo fortemente atrelado à clínica, com foco na obesidade. $\mathrm{O}$ processo educativo que envolve mudança de padrão alimentar parte da clínica e centra-se nela, fazendo da prescriçãoo o cerne da questão.

\section{Conclusão}

Há uma crítica recorrente apontada na literatura acerca dos limites de formação do nutricionista, sobretudo no que se refere às competências relacionadas a educação, promoção de saúde e trabalho em equipe. Sem desconsiderar a necessidade premente de mudança nos currículos, é preciso reconhecer que isso se dá em longo prazo. A realidade, contudo, mostra um número expressivo de nutricionistas inseridos nesse nível de atenção, cuja atuação viabiliza e mobiliza resultados ou se paralisa diante dos desafios impostos pela prática. Evidencia-se, portanto, certo descompasso entre a formação e o cenário da prática, recheado de desafios.

Nesse percurso, é preciso considerar que diversos profissionais da área de saúde ensaiam seus processos de trabalho na atenção básica e tecem essas mesmas críticas em relação aos limites de sua formação. A crítica sobre a necessidade de se reverem os currículos da saúde, em função desse espaço de atuação na atenção básica do SUS, não está restrita à nutrição. Reconhecemos, sim, a necessidade de mudar, o que inclui reforçar saberes e habilidades comuns a todos os profissionais da saúde em sua atuação 
no campo técnico-operacional, exigindo transformaçôes importantes nos processos de trabalho, tanto da equipe mínima como da equipe multidisciplinar na atenção básica do SUS.

O campo social requer ações que colaborem para a formulação de estratégias de organização em rede dos territórios, no sentido de promover saúde, e que sejam condizentes com o modo de funcionamento peculiar a cada um. Isso envolve a construção e a manutenção de vínculo com a comunidade, desafio que exige novas formas de cuidar, em que a autonomia é pedra angular, diferente do ambiente hospitalar, no qual os sujeitos estão sob tutela. Impõe-se, assim, aprofundar-se na organização e no funcionamento dos sistemas universais de saúde, em sua coprodução social e cultural, relativa a cada povo e à sua cultura.

As ações educativas vinculadas ao campo de alimentação e nutrição ainda carregam o ranço das concepções articuladas nos primórdios dessa prática, fundamentadas no mito da ignorância (Santos, 2005), como determinantes da fome e da desnutrição da população pobre. O cenário político que se desenhou na sociedade brasileira, na segunda metade do século passado, trouxe algumas mudanças que apontam para determinantes sociais de saúde de uma forma mais ampla, reconhecendo a educação em saúde na interface com a cidadania e a qualidade de vida.

Alguns estudos feitos por Recine e Vasconcelos (2011) reconhecem a atenção básica como locus privilegiado para o avanço da promoção de uma alimentação saudável. Apesar do reconhecimento geral acerca da relevância que a educação em saúde e a promoção de saúde na atenção básica apresentam, ainda há um conflito sobre o lugar de ambas, bem como sobre o que as diferencia, como ressalta Santos (2005). Não é possível educar para transformar sem um compromisso político bem-definido, como amplamente lembrado por Paulo Freire $(1979,1987)$. Não há neutralidade nos processos educativos. É preciso ter clareza sobre qual projeto de sociedade temos em vista ao educar, e se há potencial para transformar no sentido do ideário do SUS.

Uma análise relevante sobre a PNAN realizada por Santos (2005) observa uma quase superposição dos conceitos de promoção de práticas alimentares saudáveis e educação alimentar e nutricional. Também ressalta que a transmissão de conceitos ainda é a lógica que parece perpassar as concepções de educação em saúde. Santos aponta, no atual contexto político, certo paradoxo nas proposições sobre educação alimentar e nutricional, pois, ao mesmo 
tempo que se reconhece sua importância estratégica, deixa-se de definir, de forma clara, o espaço ocupado no norte político defendido. Acrescenta que, como a educação alimentar e nutricional está em todos os lugares da PNAN, mas não tem uma definição clara, todos os lugares passa a ser lugar nenhum, chamando a atenção para o risco de se reconstruir o mito da ignorância em concepções de promoção de saúde e educação em saúde que responsabilizam o indivíduo pelas mudanças, reduzindo o processo de saúde e doença a escolhas individuais.

Em geral, há uma compreensão equivocada do processo complexo que envolve a mudança de comportamento alimentar. Boog (2008), nas pesquisas feitas em 1999, já apontava para certo descrédito por parte de médicos e enfermeiros sobre a efetividade de haver mudança no comportamento alimentar. Além disso, é preciso considerar alguns condicionamentos externos, os quais, não raro, inviabilizam a mudança dos hábitos alimentares, impedindo eventuais transformaçôes nesse campo. Cabe, portanto, indagar: como é possível iniciar e se envolver em atividades cujos resultados não são convincentes?

O cenário de transição epidemiológica exige ações que ultrapassam a lógica individual. É preciso ter criatividade para pensar em ações no âmbito comunitário efetivadas em conjunto, com o potencial de gerar transformações coletivas. A educação em saúde, no sentido de autonomia para escolha de uma alimentação saudável, é algo muito nebuloso no universo da atenção básica, exigindo, portanto, um olhar transdisciplinar.

Sem dúvida, as orientações e o monitoramento dispensados no seguimento de uma dieta são ações, mas, independentemente de sua importância, mostram-se insuficientes para efetivar a mudança de comportamento relacionada a hábitos alimentares. Há uma premência de pensarmos, de forma criativa, em ações comunitárias que possam gerar novos significados no âmbito comunitário, que possam fazer ressonância nas individualidades e fazer frente à comunicação midiática, que reforça padrões de alimentação não saudáveis. É preciso ir além do senso comum e mais além ainda do enfoque biologicista quando se trata de pensar em estratégias que colaborem para a mudança de hábitos, sobretudo de hábitos alimentares, levando-se em conta sua carga simbólica ligada à sobrevivência e à sociabilidade humana. Isso demanda aprofundamento nos estudos sobre práticas alimentares e de comensalidade, com enfoque comunitário, antropológico e psicossocial. 
Esta pesquisa desvelou um processo de trabalho ancorado em concepções de saúde dos modelos privado e da clínica tradicional, enraizados nas ações e no modo de se organizar dos profissionais e da população. Modelos cujas raízes sufocam e devoram as atividades centradas na promoção da saúde. No entanto, este estudo, em face de seus limites, também deixa lacunas e lança algumas perguntas. Compreender como a população vivencia e reforça o modelo privado de saúde, influenciando o modo de organização dos serviços da atenção básica, é um dos aspectos que demandam aprofundamento. Outra questão se refere à maior compreensão acerca da construção de padrões alimentares na perspectiva da complexidade, integrando dimensões diversas, inclusive a psicossocial e a antropológica.

Ainda é preciso decifrar muitos aspectos e explorar diversos processos de trabalho associados à educação alimentar e nutricional, com vistas a se efetivarem ações de promoção de saúde e que resultem em transformação, no sentido de garantir direitos de cidadania que subsidiem a consolidação do SUS.

\section{Referências}

ASSIS, A. M. O. et al. "O Programa Saúde da Família: contribuições para uma reflexão sobre a inserção do nutricionista na equipe multidisciplinar". Rev. Nutr. [online], v. 15, n. 3 , 2002, pp. 255-66.

BOOG, M. C. F. "Atuação do nutricionista em saúde pública na promoção da alimentação saudável”. Revista Ciência \& Saúde, Porto Alegre, v. 1, n. 1, jan./jun. 2008, pp. 33-42.

BRASIL. Conselho Nacional de Saúde. Ministério da Saúde. Resolução no 196/96. Diretrizes e Normas Regulamentadoras de Pesquisa envolvendo seres humanos. Brasília: Ministério da Saúde, 1996. Disponível em: http://conselho.saude.gov.br/comissao/conep/resolucao. html. Acesso em: 31 out. 2009.

— Ministério da Saúde. Secretaria de Atenção à Saúde. Departamento de Atenção Básica. Política Nacional de Atenção Básica. Brasília: Ministério da Saúde, (2006).

—. Ministério da Saúde. Portaria no 154, de 24 de janeiro de 2008. Núcleos de Apoio à Saúde da Família. Disponível em: http://bvsms.saude.gov.br/bvs/saudelegis/gm/2008/ prt0154_24_01_2008.html. Acesso em: 27 dez. 2011.

—. Ministério da Saúde. Secretaria de Atenção à Saúde. Departamento de Atenção Básica. Política nacional de alimentação e nutrição. 1. ed. Brasília: Ministério da Saúde, 2013.

CUNHA, G. T. A construção da clínica ampliada. São Paulo: Hucitec, 2005.

CZERESNIA, D. et al. Os sentidos da saúde e da doença. Rio de Janeiro: Fiocruz, 2013.

DIAS, F. A. C. e DIAS, M. S. A. Território, cultura e identidade. Rio de Janeiro: Abrasco, 2010. FERNANDEZ, P. M. F. et al. "Programa Saúde da Família e as ações em nutrição em um distrito de saúde do município de São Paulo". Ciênc. saúde coletiva [online], v. 10, n. 3, 2005, pp. 749-55. 
FERREIRA, V. A. e MAGALHAES, R. "Nutrição e promoção da saúde: perspectivas atuais". Cad. Saúde Pública [online], v. 23, n. 7, 2007, pp. 1.674-81.

FREIRE, P. Educação e mudança. 20 ed. Rio de Janeiro: Paz e Terra, 1979.

- Pedagogia do oprimido. 22 ed. Rio de Janeiro: Paz e Terra, 1987.

GÓIS, C. W. L. Saúde comunitária: pensar e fazer. São Paulo: Hucitec, 2008.

MARTINS JÚNIOR, T. et al. "A residência multiprofissional em saúde da família de Sobral, Ceará”. SANARE, Sobral, v. 7, n. 2, jul.-dez. 2008, pp. 23-30.

MATTOS, R. A. "Integralidade e a formulação de políticas específicas de saúde". In PINHEIRO, R. e MATTOS, R. A. (orgs.). Construção da integralidade: cotidiano, saberes e práticas em saúde. Rio de Janeiro: UERJ/IMS/Abrasco, 2003, pp. 45-59.

MINAYO, M. C. S. O desafio do conhecimento: pesquisa qualitativa em saúde. 4 ed. Rio de Janeiro: Hucitec, 1996. 269p.

ORLANDI, E. P. Análise do discurso: princípios e procedimentos. Campinas. SP: Pontes, 2000.

PADUA, J. G. e BOOG, M. C. F. "Avaliação da inserção do nutricionista na rede básica de saúde dos municípios da região metropolitana de Campinas”. Rev. Nutr. [online], v. 19, n. 4, 2006, pp. 413-24.

RECINE, E. e VASCONCELLOS, A. B. "Políticas nacionais e o campo da Alimentação e Nutrição em Saúde Coletiva: cenário atual”. Ciênc. saúde coletiva [online], v. 16, n. 1, 2011, pp. 73-9.

SANTOS, A. C. "A inserção do nutricionista na Estratégia da Saúde da Família: o olhar de diferentes trabalhadores da saúde". Família Saúde Desenvolvimento, Curitiba, v. 7, n. 3, set.-dez. 2005, pp. 257-65.

SANTOS, L. A. S. "Educação alimentar e nutricional no contexto da promoção de práticas alimentares saudáveis". Rev. Nutr. [online], v. 18, n. 5, 2005, pp. 681-92.

VASCONCELOS, F. A. G. "O nutricionista no Brasil: uma análise histórica”. Rev. Nutr. [online], v. 15, n. 2, 2002, pp. 127-38. 